\section{Auf die Straße}

_ „Man muss vom Weg abkommen, um nicht auf der Strecke zu bleiben.“ Dieses Zitat von Hans Zaugg, einem Schweizer Architekten und Designer, passt meines Erachtens zu dem, was gerade in der deutschen Physiotherapielandschaft passiert: Physiotherapeuten gehen auf die Straße. Sie informieren über ihre schlechte Vergütung und verschaffen sich Gehör.

_Die üblichen Bemühungen gegen die seit Jahren immer miserabler werdende Bezahlung führ(t)en zu nichts. Trotzdem waren und sind sie richtig: Wir reflektieren, was wir tun, wir forschen, liefern Wirksamkeitsnachweise, bieten Qualität, haben zufriedene Patienten und setzen maßgeblich gesetzliche Forde-

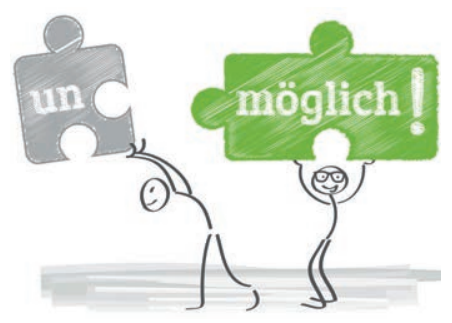
rungen wie Reha vor Pflege um. Ökonomisch betrachtet, trägt das für den einzelnen Therapeuten kaum Früchte. Teure Ausbildung, viele Fortbildungen, große Weiterbildungen, Studium - all das lässt der Leistungskatalog der Kostenträger weitgehend unberücksichtigt.

_ Jetzt also demonstrieren Physiotherapeuten und andere Therapieberufe auf der Straße. Sie teilen der Öffentlichkeit ihre „besch... eidene“ Situation mit. Ein guter Plan. Jeder da draußen soll wissen, was Physios leisten und was sie verdienen. Nur so kann sich die Öffentlichkeit bei der Durchsetzung gerechtfertigter Forderungen mit den Therapeuten solidarisch verhalten und sie unterstützen.

_ Lassen Sie uns diesen Schritt auf die Straße nicht verwässern durch die Frage „Wer hat's erfunden?“. Wichtig ist, dass es passiert und weiterhin passiert. Es gibt immer Initiatoren und Trendfollower. Entscheidend ist der Trend. Lassen wir ihn zur Bewegung werden, die uns weiterbringt.

Ihre

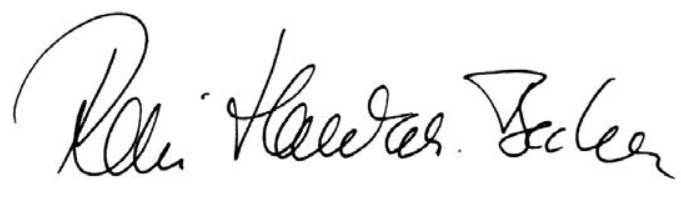

Veränderung ist möglich.

Tragen wir unser

Anliegen beherzt in die

Öffentlichkeit.

\section{ZU GEWINNEN}

In jeder physiopraxis werden attraktive Gewinne verlost. Möchten Sie einen ergattern, klicken Sie unter www.thieme.de/physiopraxis auf "Gewinnspiel“.

Und das gibt es in dieser Ausgabe zu gewinnen:

CDs

3 CDs „Stressfrei durch Progressive Relaxation“

Seite 67

und außerdem ...

1 „Herzmodell“

2 Lehrtafeln „Häufige

Herzerkrankungen“

1 Tischlampe „Mr. P“

1 Eintrittskarte für

den physiotag auf

der FIBO

Seite 34

Seite 34

Seite 37

Seite 46 